\title{
Inflação e Mercado como sistemas alternativos de regulacão
}

\author{
Paul Singer
}

\section{Introdução}

Este é um trabalho muito exploratório, inspirado pela idéia de que a inflação possa ser - em democracias capitalistas contemporâneas - mais do que uma aberração econômica. Do ângulo da economia política, está claro que a inflação desempenha muitas vezes funçōes, particularmente em relação a conflitos distributivos. $O$ poder de distribuir valor criado do nada permite ao árbitro governamental resolver conflitos sem negar reivindicaçōes ou infligir perdas. Mas, aqui, me aventuro mais longe nesta trilha, perguntando se inflações que são pesadas e continuam por décadas não se tornam sistemas de macrorregulação para a economia como um todo.

A hipótese parece bem fundamentada, ao menos para países como o Brasil, que experimentou continuamente inflação desde os anos 40 , ao menos, e suporta uma inflação de três dígitos desde 1980. Durante os anos 60, o Brasil era parte do que parecia ser a síndrome inflacionária

latino-americana, mas desde então o número de países sob inflação pesada e permanente está crescendo rapidamente. A síndrome está atingindo preferencialmente países em intensa mudança econômica e social.

O tamanho e a permanência da inflação, nestes casos, $€$ um sinal seguro de seu grande impacto na vida social. Mas, como a vida social se reproduz sob tais circunstâncias, sua regularidade é condicionada não apenas pela inflação mas também pelas incessantes tentativas de se livrar dela. E, obviamente, pelo repetido fracasso destas tentativas.

Na primeira parte deste trabalho, o problema é por que a inflação permanente torma-se eventualmente pesada mas nāo vira hiperinflaçāo. A partir daí, examina-se o funcionamento duma economia regulada por inflação, tomando em conta fatores econômicos assim como políticos. Na segunda parte, $\mathrm{O}$ problema é como economias, que sảo capazes de evitar a inflação, são reguladas. Aqui, a experiência dos países capitalistas desenvolvidos torna-se relevante, particularmente de 1973 em diante, quando perdas econômicas tiveram que ser alocadas e isso ocasionou uma vaga inflacionária que durou vários anos. A estabilização tendo tido êxito, o mercado foi restaurado como regulador destas economias. Mas isso exige uma explicação política, que leva a especular sobre o futuro do movimento operário nestes países. Finalmente, na terceira parte, conclusōes mais abstratas sobre estagnação econômica, conflitos distributivos e inflação são tiradas.

Como é usual em trabalhos exploratórios, nenhuma das pistas foi aprofundada. Uma avaliação parece necessária para verificar se vale a pena prosseguir ao longo de tais linhas.

\section{Inflação como Sistema de Regulação}

A inflação é demasiadamente encarada como anomalia, como mal episodico, que deve e pode ser curado por políticas adequadas de ajustamento. Mas, há países em que a 
inflaçâo é crónica, sendo uma característica permanente da vida econômica, social e polf́tica. Na America Latina, tais países săo em grande número e nos anos $\mathbf{8 0}$ passaram a ter a companhia de vários outros (México, Colômbia e Venezuela). É concebível que a inflaçāo crônica também esteja se tornando a condição de países em transiçāo da economia centralmente planejada à economia de mercado. Sem mencionar outros Países Recentemente Industrializados (PRI) da Ásia e Europa, em que a inflação tambem É significativa e permanente.

Considerando unicamente países capitalistas, talvez devêssemos classifica-los em dois tipos, do ponto de vista de seus sistemas de regulação:

a) paises em que o ajustamento da demanda global à oferta global é realizado mediante polfticas fiscal e monetária que têm como alvos o nível de atividade e de emprego e - Balanço de Pagamentos;

b) países em que as polf́ticas fiscal e monetária são condicionadas pela inflaçăo passada, de modo que o ajustamento da demanda global à oferta global tem de ser realizado mediante aumento de preços, isto $\epsilon$, pela inflação presente.

Para examinar o funcionamento da inflação como sistema de regulaçāo, consideremos uma economia que se encontra sob inflação pesada há tantos anos que:

a) as causas originais da inflaçāo estão esquecidas; os únicos fatores relevantes sāo os que fizeram a inflação atingir seu nível atual e estão ainda em ação, possivelmente tendendo a levá-la a picos mais elevados;

b) a expectativa unânime $\epsilon$ que a inflação prossiga, de modo que a maioria dos preços, impostos, alugueis, juros e taxa de câmbio nominais estão indexados, isto $\epsilon$, são reajustados em diferentes períodos de tempo, de acordo com a variação de diferentes índices de preços.

Em tal situaçăo, a política fiscal tem uma finalidade suprema: manter sob o controle o déficit público. Há deficit porque a inflaçāo expande a despesa pública antes de aumentar a receita tributária. Como impostos têm de ser recolhidos sobre transações ou rendas passadas, os governos sempre estáo pagando os preços (ou salários) de hoje com receitas tributárias que correspondem a preços de vários meses antes. A inflação entre estes momentos no tempo ocasiona uma perda inevitável de receita real. Para combater o déficit público, a despesa pode ser contida e/ou impostos podem ser elevados. Ambos sāo difíceis de alcançar. Cortes de despesa ferem interesses políticos, particularmente em sociedades em rápida mudança, como as de PRI ou de Novas Economias de Mercado (NEM). A mudança social exige amplo dispêndio público em infra-estrutura econômica, em serviços sociais e em infra-estrutura social. O lógico seria não reduzir o dispendio, mas elevar impostos. Mas isso é duplamente difícil porque a tributação aumentada $\epsilon$ incorporada a todos os índices de inflação e resulta em rendas reajustadas após o pagamento de impostos que literalmente expulsam a elevação tributária mediante inflaçāo mais alta. Suponha que um imposto ad valorem de $10 \%$ é coletado num perfodo de tempo em que uma inflação de $30 \%$ the retira $23 \%$ de seu valor real ${ }^{1}$. Para combater o déficit, 0 imposto 6 elevado a $15 \%$. Um imposto maior estimula uma sonegação maior. Suponhamos que a elasticidade da sonegação ao aumento do imposto seja um, de modo que uma elevação de $50 \%$ do imposto induza uma sonegação marginal de $50 \%$. Assim, a receita tributaria nominal cresce de 100 para 125 (em vez de 150, que teria ocorrido se a sonegaçăo tivesse permanecido constante). Se a inflaçăo no intervalo de tempo aumenta,

1 Receita tributária nominal $=100$; findice de preços $=130 ; 100 / 130=0,77$. 
principalmente devido à elevação do imposto, de $30 \%$ para $62,3 \%$, o valor real da receita do imposto fica igual ao que era antes ${ }^{2}$. Este exemplo numérico é apenas para mostrar como é improvável que, sob inflação pesada permanente, uma elevação tributária nominal possa ocasionar alterações significativas da receita tributária real.

A política monetária $\epsilon$ em larga medida condicionada pelo resultado da política fiscal. Como é muitas vezes o caso, déficits públicos, persistindo por longos períodos, acumulam-se em dívidas públicas muito grandes, cujo serviço sói ser uma das causas principais do déficit público presente. Isso estreita as alternativas de política monetária. Se uma política mais restritiva é adotada, a emissão de títulos, para financiar o déficit público ou grande parte do mesmo, puxa a taxa de juros para cima. Não muito dinheiro novo sera posto em circulação, de modo que a escassez de meios de pagamento ${ }^{3}$ ratifica o aumento da taxa de juros. Isso deveria reduzir a demanda efetiva e ajudar a reprimir a inflação. Mas, no meio tempo, a maioria dos fazedores de preços (price makers) elevarāo o seu mark-up para alcançar uma taxa de retorno sobre o seu capital proporcional à taxa mais alta de juros. Assim, inicialmente a inflação sobe em vez de descer, o déficit público será ainda maior, tanto devido aos pagamentos de juros maiores sobre a dívida pública, como devido à inflação maior, que eleva muito mais o dispêndio público do que a receita tributária. Isso por sua vez forçará a Autoridade Monetária a restringir ainda mais o crédito e a oferta da moeda, até que a recessão, causada pelo declínio da demanda efetiva, exerça tal pressão para baixo sobre os preços que anule as reaçóes que aceleram a inflação.
Uma política monetária restritiva consegue eventualmente baixar a inflaçāo ao transferir o ónus do ajustamento principalmente sobre os tomadores de preços (price takers) empresários pequenos e médios em mercados concorrenciais - e os assalariados. Os tomadores de preços não podem jogar o ônus do pagamento de juros mais elevados sobre seus clientes e são assim forçados a estreitar suas margens de lucro, ainda mais quando confrontados com uma demanda em declínio. Neste processo, muito são arruinados. Os

trabalhadores assalariados também têm que enfrentar uma forte redução da demanda por sua força de trabalho. $O$ aumento do desemprego debilita a indexação dos salários, que normalmente se encontra, de todos os modos, algo abaixo da inflação corrente. Sob a pressão dos desempregados, desenvolve-se um mercado negro de trabalho - o salário real cai -, reforçando poderosamente o decréscimo dả demanda efetiva.

Embora economicamente viável, uma política monetária restritiva provoca crescente resistência social, a qual em algum momento se desdobra em formidável oposição política. Como esta política fere os interesses da maioria do eleitorado e traz resultados positivos - a queda da inflação - só mais tarde, torna-se muito provável que seja aniquilada pela oposição política antes que tenha muitas chances de exibir suas virtudes estabilizadoras. Para viabilizar a política monetária restritiva politicamente, o governo $e$ forçado a compensar seus efeitos mais dolorosos mediante subsídios e transferências. Agricultores em dificuldades recebem créditos especiais com juros menores, possuidores de imóveis hipotecados recebem subsídios, trabalhadores desempregados recebem indenização.

2 Receita tributária nominal $=125 ;$ índice de preços $=162,3 ; 125 / 162,3=0,77$.

3 Se a inflação fosse alta, mas estável, a demanda por moeda deveria crescer no mesmo ritmo que os preços subissem. Se a inflação acelerasse, o custo de reter especie aumentaria e em consequiência a demanda por moeda deveria aumentar menos do que a nova taxa corrente da inflação. E vice-versa. 
Tudo isso deságua no déficit público, tornando a política monetária ainda mais restritiva, acelerando a inflação e retardando seus efeitos estabilizadores. $O$ retardo resulta do fato de que todas medidas compensatórias aliviam a recessão, contendo o declínio da demanda efetiva. Por fim, uma mistura desconfortável de políticas restritivas e permissivas é posta em prática, que mais provavelmente estabiliza a inflação em alto nível em vez de derrubá-la.

A história de economias sob inflaçāo permanente e pesada está cheia de tais episódios. Em lugar algum, agüenta-se a inflação passivamente, sem repetidas tentativas de livrar-se dela. A luta contra a inflação, nestes países, torna-se verdadeira obsessão e $e$ reencetada por cada novo governo e por cada novo ministro da Fazenda.
Embora a inflação seja vista universalmente como sendo um mal muitas vezes como o mal -, as perdas decorrentes da luta contra a inflação, mediante redução da demanda efetiva, tornam-se insuportáveis após certo tempo e a revolta assim provocada, que freqüentemente se exprime nas urnas, derrota a aliança no poder e impõe políticas fiscais e monetárias mais permissivas. As sucessivas batalhas contra a inflação, terminando em derrotas mais ou menos completas, formam a dinâmica rotineira destas economias. É provável que uma inflaçāo pesada - digamos de três dígitos -, se não fosse sujeita a persistentes tentativas de contenção, explodiria rapidamente em

hiperinflação. Deste ponto de vista, os fracassos na luta contra a inflação certamente não ficam sem efeitos. As penalidades impostas por repetidas

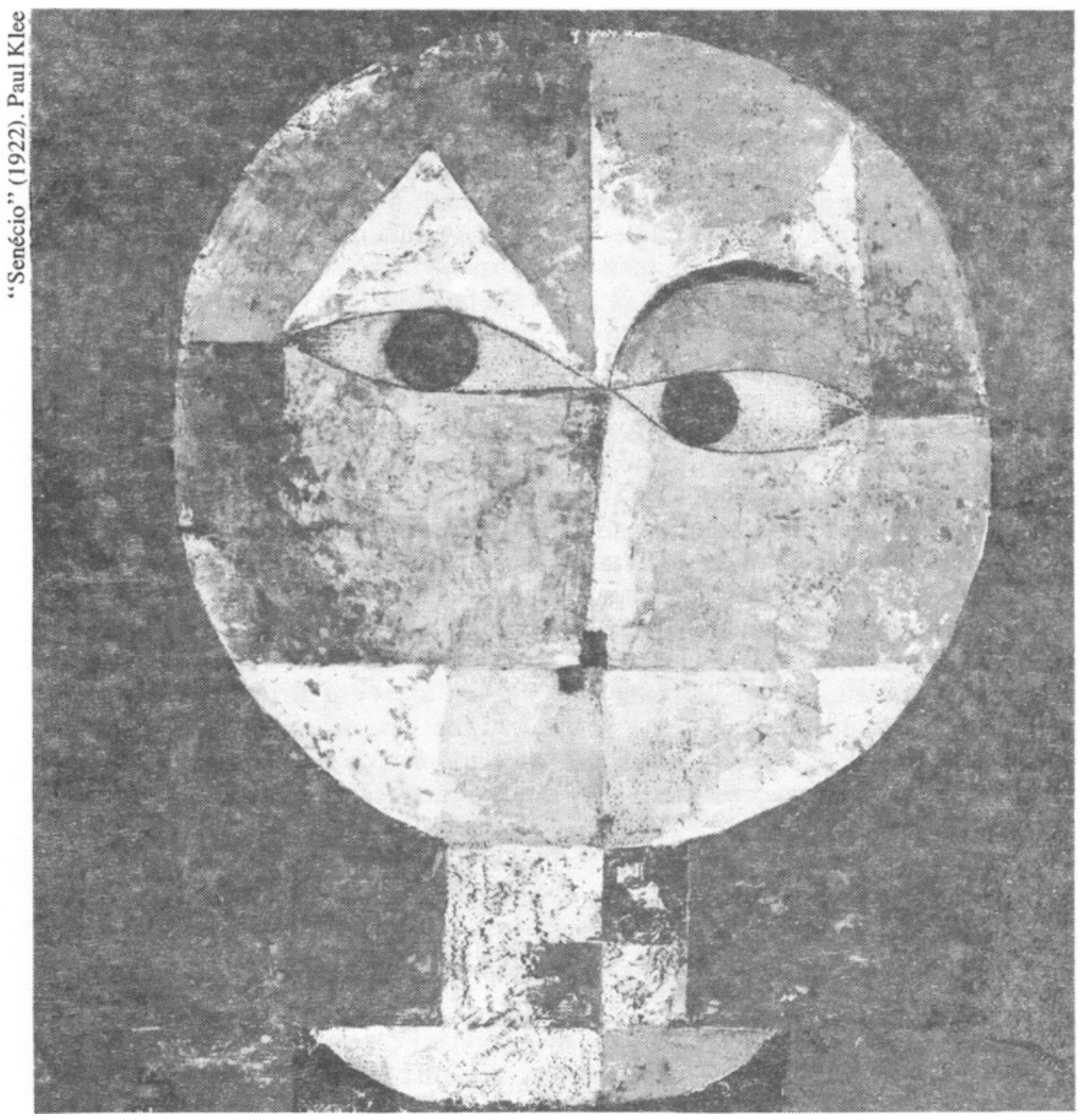


recessões não são, afinal, inteiramente em vão. Suas vítimas são recompensadas pela relativa estabilização do ritmo de aumento dos preços, aumento esse que, graças à indexação, torna-se depois de algum tempo neutro do ponto de vista da repartição da renda.

Este é o modo pelo qual a inflação torna-se permanente. Mas como funciona uma economia sob a pressão de valores nominais em contínua ascensão? Obviamente, os preços somente podem crescer porque os compradores estão preparados para pagá-los. Isso define uma situação em que a demanda global excede cronicamente a oferta global. Mas a demanda global é contida por políticas fiscal e monetária restritivas, de modo que os preços possam subir agora a uma velocidade muito semelhante à que o fizeram no passado. Ao menos, este seria o resultado lógico da indexação: se todos os preços condutores (preços dos bens mais básicos, no sentido do sistema de Sraffa), crescem no mesmo ritmo que o nível médio dos preços, a taxa de inflação, requerida para ajustar demanda e oferta globais, deveria ser constante, a não ser que elementos da economia real - preferências dos consumidores, custos de produção, concorrência estrangeira etc. mudem.

Mas, na realidade, um modelo de equilibrio de ajustamento inflacionário como esse ignora um fato

fundamental: sob inflação pesada, permanente, um conjunto de conflitos distributivos entrelaçados está sempre mudando preços relativos, salários, aluguéis etc. e, deste modo, modificando a repartição geral da renda. Todos os valores e rendimentos reais estão sempre se movendo para cima ou para baixo, devido ao fato básico que, embora a cada momento alguns valores estão subindo, a maioria deles não está. Esta é a diferença decisiva entre inflação pesada e hiperinflação. Sob hiperinflação, o mais provável é que todos os preços subam todo dia. Mas, sob inflação comum, particularmente

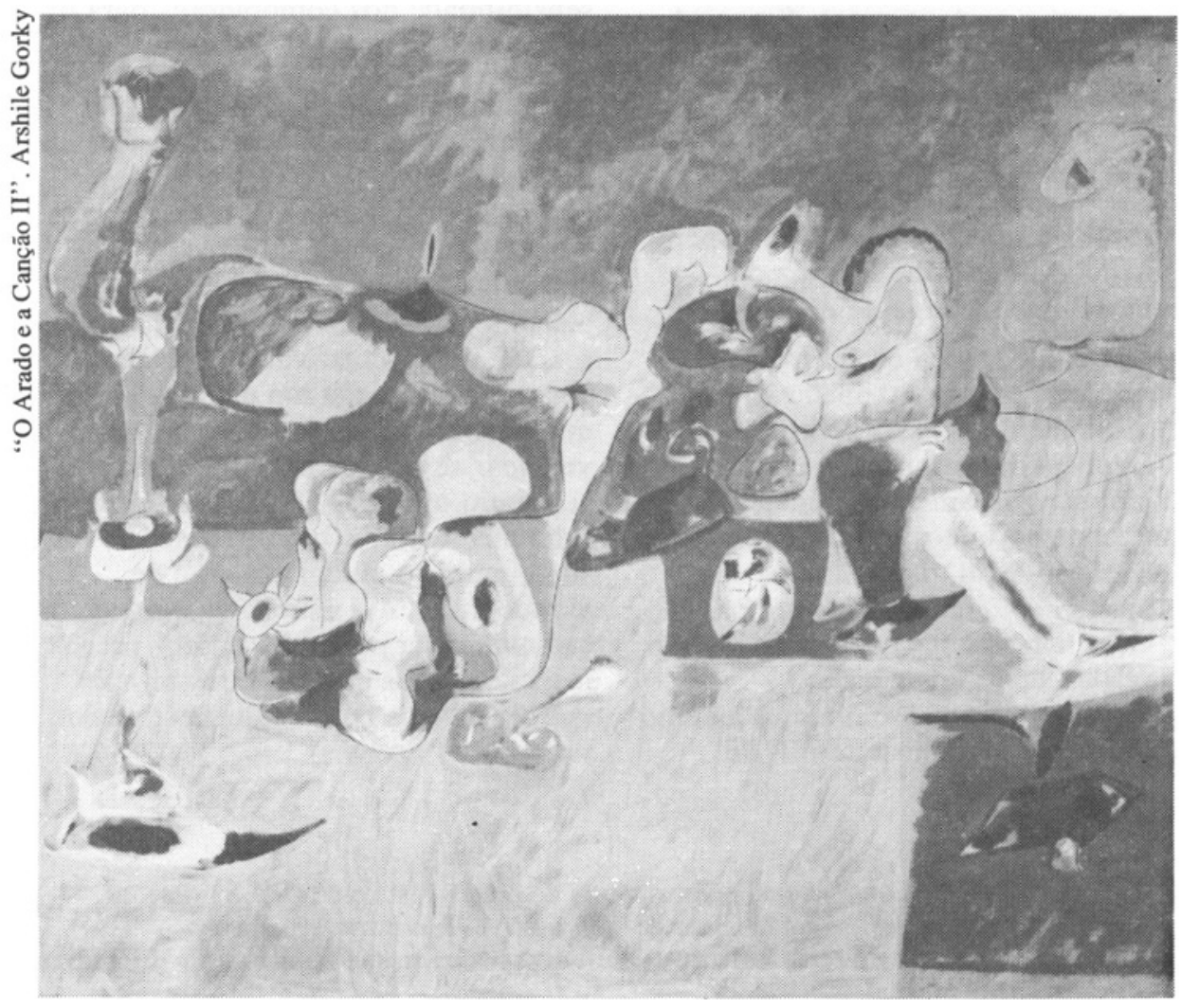


uma inflação que é pesada mas não está "disparando", cada valor nominal muda em certos intervalos, mas apenas alguns valores financeiros sobem todo dia. A maioria dos valores contratuais - como salários e aluguéis - são reajustados cada mês, par de meses, trimestre etc. Preços de muitos bens no atacado também são "fixados" pela duração de períodos de suprimento contratualmente definidos. Numa situação assim, $a$ cada momento a renda é redistribuída aos poucos agrupamentos cujos preços (ou salários, aluguéis etc.) estão aumentando agora; os outros agentes, que estão pagando estes preços mais altos, sofrem perdas de renda.

Cada agrupamento (composto essencialmente por vendedores da mesma mercadoria: um bem, um serviço, força de trabalho sob o mesmo contrato coletivo etc.) perde renda real durante a maior parte do tempo, à medida que suas compras se tornam continuamente mais caras, enquanto seu rendimento nominal não muda; então chega o momento em que o seu preço é reajustado, de modo que possa recuperar suas perdas passadas e enfrentar perdas futuras. Para cada agrupamento, o montante de reajustamento de seu rendimento nominal é muito importante, já que ele proporciona uma margem maior ou menor de segurança contra aumentos futuros de seus custos, que se espera que ocorram até que sua vez de reajustamento chega de novo.

Deste modo, todos os agrupamentos se esforçam para maximizar o reajustamento de seus preços e esta é a essência da maioria dos conflitos distributivos. Um certo número de preços importantes está sujeito à indexação legal, de modo que seu reajustamento depende de normas legais. Importantes lutas políticas são travadas sobre tais normas, particularmente sobre o reajustamento de salários, aluguéis e tarifas de serviços públicos, como as passagens de ônibus; menos abertas mas nem por isso menos intensa são as lutas sobre o reajustamento de diferentes impostos, taxas de câmbio, taxas de juros e preços de combustíveis, energia elétrica, matérias-primas básicas e preços de suporte de produtos agrícolas. Outros preços não estão sujeitos a normas legais mas são livremente barganhados no mercado. Mas nem todos os mercados são igualmente competitivos. Em muitos, vendedores e/ou compradores têm considerável grau de monopólio. Sob inflação pesada, a distinção entre fazedores de preços e tomadores de preços é crucial, muito mais do que sob inflação leve ${ }^{4}$ ou estabilidade da média de preços. Fazedores de preços podem transferir por inteiro aumentos de custos aos seus preços, mantendo seus rendimentos reais intactos enquanto média em cada período. Tomadores de preço não podem fazer isso, a nāo ser que a demanda por seus produtos tenha baixa elasticidade-preço. $O$ que de fato se torna mais freqüente quando uma inflação pesada embota a sensibilidade dos compradores para os diferenciais de preços.

Normalmente, qualquer pessoa que vai comprar itens de pequeno valor (bens de consumo corrente) tem uma boa idéia dos preços que espera pagar. Mas, quando os preços estão aumentando rapidamente e a taxa de aumento torna-se impredizivelmente grande, as expectativas de preços se embaralham e cada um paga quase qualquer coisa, sem se preocupar em verificar se os concorrentes estão cobrando o mesmo. Isso significa que cada mercearia, açougue, farmácia ou supermercado obtém um grau de monopólio muito maior. Na prática, cada varejista pode elevar seus preços mais do que os concorrentes sem ter que temer uma perda significativa de vendas.

4 Consideremos inflações leves aumentos anuais de preços abaixo de $20 \%$ e inflaçōes pesadas quando os preços sobem mais de $50 \%$ ao ano. Tais cifras sāo apenas indicativas. $O$ peso da mesma inflação quantitativa pode ser muito diverso em diferentes arranjos institucionais. 
Como resultado deste conjunto de conflitos distributivos aguçados, a inflação se encontra sob constante pressão para cima. Se preços condutores escapam ao controle, devido ao comportamento de agrupamentos dotados de maior grau de monopólio ou maior poder de pressão sobre o Estado, a indexação difunde o aumento à maioria dos outros preços, de modo que os agrupamentos que tomaram a dianteira rapidamente perdem seus ganhos relativos. Eles podem, é claro, reagir aumentando seus preços ainda mais, de modo que a inflaçăo se acelera continuamente até se tornar hiperinflação. Para evitar este perigo, os governos tratam de manter os conflitos distributivos sob estrito controle, mediante regulaçōes específicas de valor e solapam a

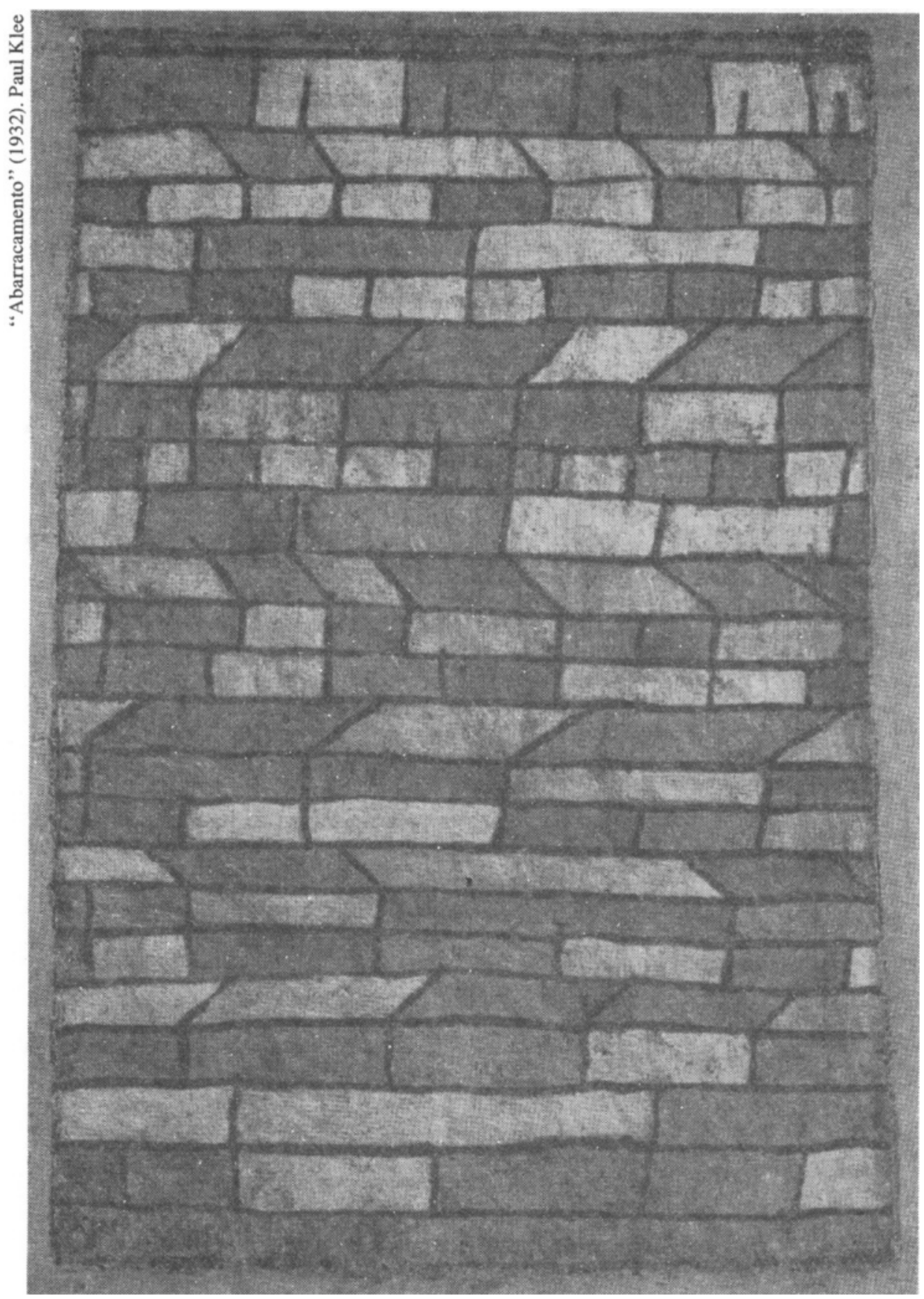


demanda efetiva mediante sucessivas políticas de estabilizaçāo.

É assim que a inflação, alta e duradoura o bastante para requerer indexação generalizada, funciona como sistema de regulação de economias de mercado que passam por rápida mudança econômica e social. Ela regula o comportamento econômico ao substituir os constrangimentos de mercado e de liqüidez, que aparentemente se originam da interação desenfreada dos agentes econômicos, por normas explícitas, legais e contratuais, de fixaçấo de preços. O contraste entre estes dois modos ou sistemas de regulação pode ajudar a entender as mudanças por que passa o capitalismo contemporâneo.

\section{A Regulação pelo "Mercado" de Sociedades Capitalistas Democráticas}

Descrevemos e, em certa medida, analisamos um modo estranho de regulação, em que a escassez abrangente de valores de uso (bens e serviços de consumo) se traduz em inflação pesada permanente. A escassez neste caso $\ell$ principalmente social, a demanda por mercadorias sendo produzida pela competição social. A inflação é o resultado de sobredemanda e sua permanência $e$ tornada possível pela contínua reprodução de sobredemanda. Desta maneira, o constrangimento constituído por uma demanda efetiva limitada $\epsilon$ superado, mas seu lugar $\epsilon$ tomado por um constrangimento diferente, o de uma contínua degradação de todos os valores nominais.

A escassez enquanto tal leva naturalmente a uma elevação de valores: o aumento de preços devido a uma redução de colheitas ou a uma guerra perdida pode não se reproduzir, ou seja, não tem de ser o início de um processo inflacionário. Se não for, se depois do aumento os preços forem estabilizados, a maioria das pessoas empobrece mas os ricos tornam-se ainda mais ricos do que antes, porque a distância relativa entre rendimentos importa (quando o desemprego aumenta fortemente, os serviços domésticos ficam mais baratos e mais fáceis de obter, melhorando a vida dos ricos portanto). No modo de regulação pelo qual não se permite ao nível geral de preços aumentar continuamente, a escassez se traduz em pobreza e a pobreza é alocada mais ou menos permanentemente por mecanismos de mercado. Os perdedores no jogo econômico podem obter transferências do orçamento do Estado, mas apenas até o limite definido pela diferença entre receita e os outros gastos fiscais. Este limite é muitas vezes objeto de duras lutas sociais, mas a cada momento ele está dado e não é violado.

A implicação política da regulação pelo "mercado" é que o Estado só pode redistribuir renda "marginal", uma parcela do incremento de renda, à medida que a renda global estiver crescendo. Isto é assim porque, com um nivel geral de preços estável, a renda global nominal cresce apenas na medida em que a renda real está crescendo; se o Estado fosse redistribuir mais do que o incremento da renda, alguns dos grupos de renda mais alta teriam que perder renda real. Isso não $€$ impossível, mas muito improvável. Os grupos de renda mais alta detêm a maior parte da riqueza financeira em todos os países capitalistas. Se um governo ousa privar estes grupos de parte de seus rendimentos, mesmo que em proporção muito modesta, eles reagem transferindo partes de seus ativos para fora do país 5 , causando a desvalorização da moeda nacional e perdas nas contas externas. A fuga de capital é rapidamente seguida por uma greve de inversões e ambos provocam a crise econômica, uma situação que governo algum pode tolerar por muito tempo. Há um bom número de exemplos históricos desta seqüência

5 Esta reação extremada deve ser atribuída não apenas à perda econômica, mas também ao clima político que usualmente prevalece quando uma redistribuição de renda é implementada. 
de eventos, que mostra que, sob capitalismo democrático, a extensão em que a renda pode ser redistribuída é limitada, embora longe de negligenciável a longo prazo.

Quando a economia está crescendo continuamente, como aconteceu em todos os países capitalistas desenvolvidos, de 1945 a 1973 , mesmo sem muita redistribuição da renda, a pobreza absoluta pode ser - e em vários países de fato foi - quase inteiramente eliminada. A alocação da pobreza pelo mercado foi crescentemente atenuada pelo aumento do salário real de trabalhadores não-qualificados e pelo dispêndio social em benefício da maioria dos grupos desprivilegiados. A estabilidade de preços foi viabilizada politicamente pelo incessante crescimento dos rendimentos - monetários e não-monetários.

A reversão veio após 1973, quando a maioria dos países capitalistas desenvolvidos sofreu severas perdas em conseqüência do primeiro e do segundo choques do petróleo. A regulação pelo mercado falhou então, porque as perdas de renda não puderam ser definitivamente alocadas pela interação de oferta e demanda. $O$ aumento dos preços dos combustíveis espraiou-se por muitos outros preços $e$ os sindicatos foram capazes de obter ajustamentos correspondentes de salários. As regularidades, descritas na seção "Inflação como Sistema de Regulação", se realizaram. Durante os anos restantes da década dos 70 , a maior parte dos países desenvolvidos viveu sob inflação leve mas persistente. $O$ que impediu que a inflação se tornasse pesada e permanente? A resposta não pode ser a técnica das políticas de estabilização, que é igualmente bem . conhecida em todos os países sob regulação inflacionária. Ela tem de estar na esfera política, na aceitação por parte de trabalhadores de taxas esmagadoras de desemprego e por parte dos habitantes de velhos centros industriais de rápida decadência econômica.

Tal aceitação nunca foi pacífica; greves e protestos acerbos tiveram que ser esmagados antes que a tradução sem ressalvas da escassez acrescida em empobrecimento, alocada pelo mercado, pudesse ser imposta num país após o outro. Um aspecto notável deste processo foi que as vitórias sobre a resistência da classe operária. puderam ser alcançadas em todos os países sem qualquer violação das

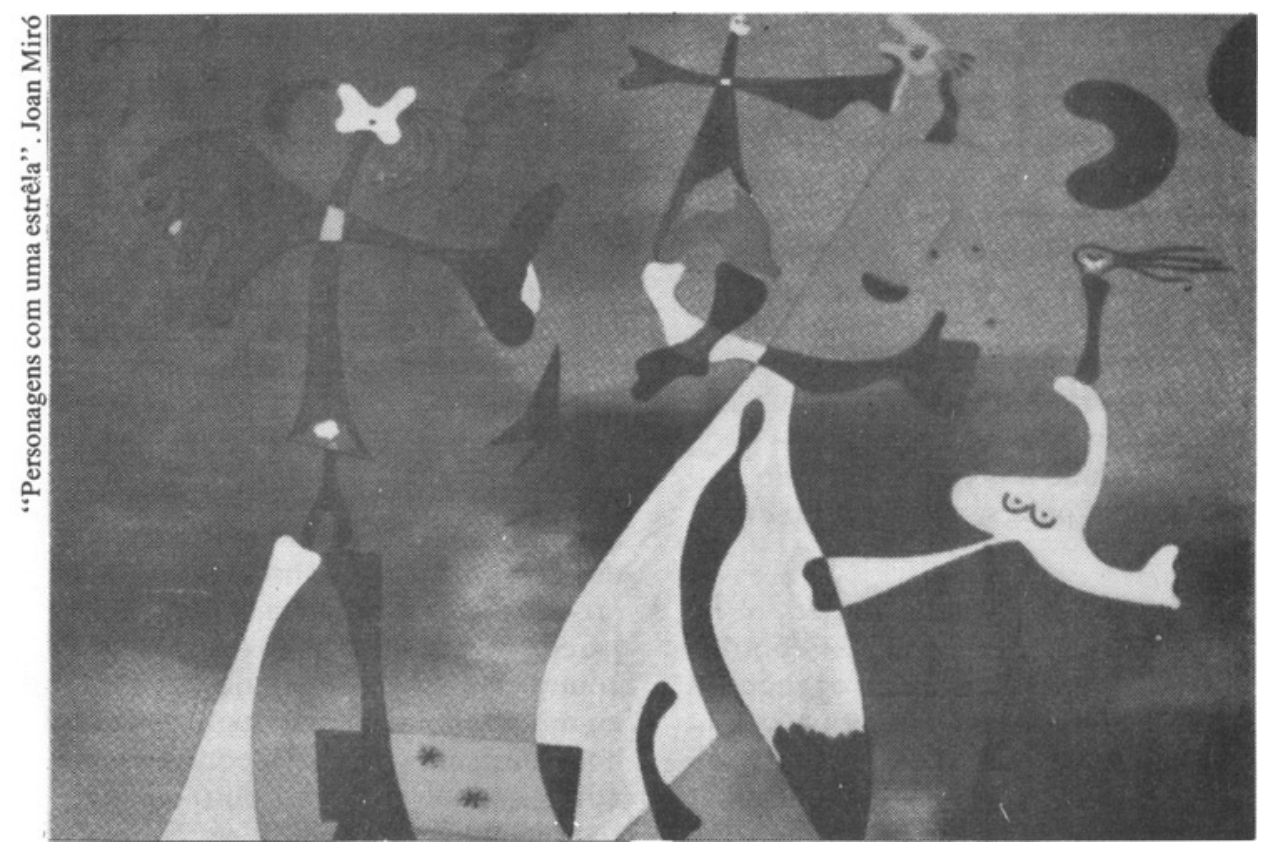


regras da democracia política. Depois do segundo choque do petroleo e a pior onda de inflação, partidos conservadores ganharam as eleições em quase todos países capitalistas desenvolvidos e revelaram força suficiente para impor sem contemplaçóes políticas de estabilização, que reverteram o sistema de regulação por inflação à alocação pelo mercado. A resposta parece ser que, nestes países, os grupos de renda mais alta são a maioria ou são capazes de reunir uma maioria atrás de si.

No início dos anos 80, a escolha com que se defrontavam muitos países capitalistas desenvolvidos era entre regulação pelo mercado e regulação por inflação. E claro que partido algum adotou inflação com indexação como sua plataforma. Todos repudiavam a inflação, mas nem todos estavam preparados para pagar o preço social exigido pela realização da estabilidade. De fato, quase em toda parte a maioria escolheu a estabilidade e, mesmo assim, após a pior recessão do após-guerra (1980-82), a inflação foi reduzida a um nível de 3 a $5 \%$, que $\epsilon$ baixo, mas significativamente mais do que zero. A opção pela regulaçāo via mercado era claramente de interesse dos proprietários de riqueza. Décadas de rendimentos continuamente em ascensão tornaram também muitos trabalhadores donos de propriedades imobiliárias e de ativos financeiros. $O$ ajustamento por meio de recessão e o fechamento de indústrias inteiras prejudicaram muita gente, mas certamente não a maioria. Ao menos, uma grande parcela dos eleitores da classe operária integrou-se à maioria neoconservadora e negou sua solidariedade aos que o mercado selecionou para serem empobrecidos.

Neste processo, o número de sindicalizados começou a se contrair e a crença de que a política econômica pode e deve manter a economia próxima do pleno emprego foi abandonada até mesmo por partidos trabalhistas. A mudança, é claro, foi muito mais ampla do que meramente a respeito de como a economia deveria ser regulada. Mas esta era a questão principal e em toda parte conceitos pre-keynesianos, que pareciam ter sido enterrados nos anos 30, foram revividos com êxito. Reviravoltas ideologicas desta monta têm que estar relacionadas a profunda transformação social. Pois bem, o que realmente mudou na maioria dos países capitalistas desenvolvidos foi o número relativo de pobres, que caiu a níveis negligenciáveis. Esta parece ser a grande conquista histórica do movimento operário, inspirado em ideologias socialistas no sentido mais amplo. A razão de ser do movimento operário, ao menos nesta forma, parece estar se exaurindo. $O$ movimento conquistou o sufrágio universal durante a primeira metade do século XX e o usou durante a segunda metade para elevar o padrāo de vida da maioria dos trabalhadores muito acima do nível de subsistência; além disso, muitos trabalhadores acumularam poupanças e se tornaram, em espírito ao menos, pequenos capitalistas. Outros perderam seu meio de vida, suas propriedades, sendo forçados a entrar nas fileiras dos desempregados ou subempregados. Sua presença conspícua no mercado de trabalho força os sindicatos a aceitar cortes de salários, com a esperança de manter seus membros nos empregos. $\mathrm{E}$ governos trabalhistas fazem políticas de ajustamento que expandem o desemprego, além de realizar a surpreendente descoberta de que lucros financiam investimentos e investimentos criam empregos - assim os lucros têm de ser protegidos contra os avanços vorazes de sindicatos ignorantes.

A conversão da maioria dos partidos trabalhistas à regulação pelo mercado das economias capitalistas - um processo ainda em andamento parece eliminar a última resistência contra este modo de regulação. Mas, agora, a regulação pelo mercado não é bem a mesma que prevalecia antes de 1930, quando o padrão-ouro e algum livre câmbio garantiam a ausência do 
governo da cena econômica. $O$ tamanho do setor público é grande demais e o grau de monopólio elevado demais para que a macrorregulação da economia fosse deixada inteiramente às variaçōes casuais dos mercados (entre os quais os financeiros desempenham a liderança). Hoje em dia, a regulação pelo mercado é, por assim dizer, produzida por políticas econômicas deliberadas, que objetivam sobretudo conter o aumento de preços. Mesmo países que têm inflação quase zero não podem estar certos que a estabilidade de preços prevalecerá no futuro. Assim, a política monetária não está automaticamente ligada ao estado do Balanço de Pagamentos, mas é parte dum conjunto de políticas econômicas mediante as quais o governo tenta administrar a demanda efetiva de modo a manter estável o nível interno de preços e as contas externas.

Pode-se perguntar se a regulação pelo mercado, como é praticada hoje, não é um caso de inflação reprimida, que tem êxito graças ao enfraquecimento dos conflitos distributivos na maioria dos países capitalistas desenvolvidos.

\section{Conclusões}

Os conflitos distributivos parecem, nos dias que correm, enfraquecidos nos países desenvolvidos, mas este certamente nāo é o caso de países que passam por transformações sociais agudas, resultantes da industrialização e/ou transição do planejamento central à economia de mercado. Nestes países, mudanças estruturais, ocasionadas pelas aplicações de tecnologia avançada, pela criação de novos ramos da indústria ou pela abertura de setores inteiros da economia à empresa privada, rompem a repartição da renda até então vigente de tal forma que a alocação pelo mercado de ganhos e perdas nunca é aceita pacificamente. Conflitos distributivos surgem e têm de ser arbitrados pelo governo. Inflação pesada e permanente é o resultado mais provável, principalmente porque, como se viu, a estabilização é social e politicamente inviável.

Parece que, uma vez deslanchada, a própria inflação suscita tantos conflitos distributivos que a permanência da inflação não depende de novos conflitos, originados em mudanças estruturais. Isso pode ser assim, mas, não havendo mudança estrutural, a repetição dos mesmos conflitos, colocando em confronto sempre os mesmos atores sociais, possivelmente estabilizaria a inflação e aumentaria as chances de sucesso da estratégia heterodoxa de estabilização. Esta pode ser a principal razão de por que a estabilização, seja ortodoxa ou heterodoxa, parece exigir que a economia permaneça estagnada para ter êxito. Se for assim, a recessão desempenha um duplo papel: o de reprimir, no curto prazo, a elevação dos preços mediante falta de demanda e, em prazo mais longo, o de impedir que surjam conflitos distributivos ao manter a repartição da renda relativamente inalterada.

A correlação entre alterações na renda e conflitos distributivos é provavelmente alta. Conflitos distributivos não surgem duma súbita percepção de que há injustiça distributiva. Eles resultam de alterações: a abertura de barganha coletiva, o aumento de necessidades devido à aparição de novos bens e serviços no mercado, a perda de rendimento real devido à inflação, o reconhecimento de oportunidades para investimento lucrativo etc. Numa economia estagnada com preços estáveis, tais alterações não são freqüentes, de modo que a probabilidade de conflitos distributivos é pequena. Numa economia sob inflação pesada permanente, no entanto, a renda muda virtualmente o tempo todo e conflitos distributivos tornam-se uma característica central da vida social. $O$ modo de regulação tem, portanto, conseqüências profundas não só na esfera econômica mas também na política.

Paul Singer é professor-titular de Economia da FEA/USP e membro do Conselho Diretor do IEA. 